\title{
10. OXYGEN AND CARBON ISOTOPE COMPOSITION AND DIAGENESIS OF EOCENE CLAY NANNO-CHALK AT DSDP SITE 287, CORAL SEA BASIN, LEG 30
}

\author{
J.V. Eade, New Zealand Oceanographic Institute, \\ Department of Scientific and Industrial Research, Wellington, New Zealand \\ and \\ T.F. Anderson, Department of Geology, \\ University of Illinois at Urbana-Champaign, Urbana, Illinois
}

\begin{abstract}
Oldest sediments in the Coral Sea Basin, cored during Leg 30 of the Deep Sea Drilling Project, are lower to middle Eocene clay nanno-chalk with layers of chert nodules near the middle and at the base of the unit.

Almost all of the nanno-chalk is semilithified with a slight increase in lithification downhole. Greater increases in lithification occur locally adjacent to the chert nodule layers.

Throughout the semilithified sediments oxygen and carbon isotope composition becomes progressively more negative downhole. This may reflect a progressive decrease in temperature of oceanic water in Eocene times when the carbonate was formed. Oxygen isotope composition in the more lithified nanno-chalk adjacent to the layers of chert nodules are about 1.0 per mil more negative than other values. This increased lithification and more negative oxygen isotope composition are attributed to diagenetic solution, recrystallization, and cementation of carbonate material associated with hydrothermal alteration and chert formation.

It is concluded that diagenesis significantly alters isotope composition and that while original paleotemperatures have been altered,the pattern of temperature changes with time can be derived from oxygen isotope composition of altered sediments where the degree of alteration is uniform or nearly so over the interval studied.
\end{abstract}

\section{INTRODUCTION}

At Site 287 in the Coral Sea Basin, 25.4 meters of core were recovered from a 57.4-meter thick sequence of Eocene clay nanno-chalk (Unit 5) the oldest sediments at the site (see 287 site report). Oxygen and carbon isotope analyses were made on 19 samples and compared to variations in composition and nature of the sediments.

\section{ANALYTICAL METHODS}

Approximately $1 \mathrm{cc}$ of the bulk sediment samples were disaggregated and washed two times by ultrasoneration in distilled water. After the sediment had settled, the water was decanted, and the ultrasonic treatment was repeated in methanol. The samples were then dried in an oven at $100^{\circ} \mathrm{C}$. Portions of each sample (25$35 \mathrm{mg}$ ) were reacted in $100 \% \mathrm{H}_{3} \mathrm{PO}_{4}$ at $25^{\circ} \mathrm{C}$ (McCrea, 1950). The evolved $\mathrm{CO}_{2}$ was purified of condensable gases and analyzed for carbon and oxygen isotope composition in a double-collecting mass spectrometer (Nuclide RMS).

\section{RESULTS}

The sediments of Unit 5 are moderately uniform throughout, consisting almost entirely of gray semilithi- fied clay nanno-chalk. The top of the chalk is at the Eocene-Oligocene regional unconformity where sediments representing approximately 20 m.y. are missing; the base is at the contact with basalt basement. A moderately well established nannofossil zonation gives an age range from about 47 to $52 \mathrm{~m} . \mathrm{y}$. for Unit 5 .

On the basis of minor differences in color and composition five subunits may be recognized (Figure 1).

Subunit 5A: (Hole depth, 179.3-182 m): Uniform yellowish-gray clay nanno-chalk.

Subunit 5B: (Hole depth, 182-196 m): Yellowishgray silica-bearing clay nanno-chalk. This differs from other subunits in having moderate amounts of siliceous thin zones of greenish-gray chalk with greater amounts of siliceous biogenic material than the surrounding sediment.

Subunit 5C: (Hole depth, 196-202 m): Yellowishgray clay nanno-chalk. This differs from other subunits in the presence of several layers of lithified chert nodules and limestone.

Subunit 5D: (Hole depth, 202-228 m): Bluish-gray clay nanno-chalk. Differs from other subunits in its bluish color and in having a large proportion of zeolites in the noncalcareous fraction. An X-ray analysis shows that about $20 \%$ of the sediment consists of the volcanically derived authigenic minerals montmorillonite, clinoptilolite, and cristobalite. 


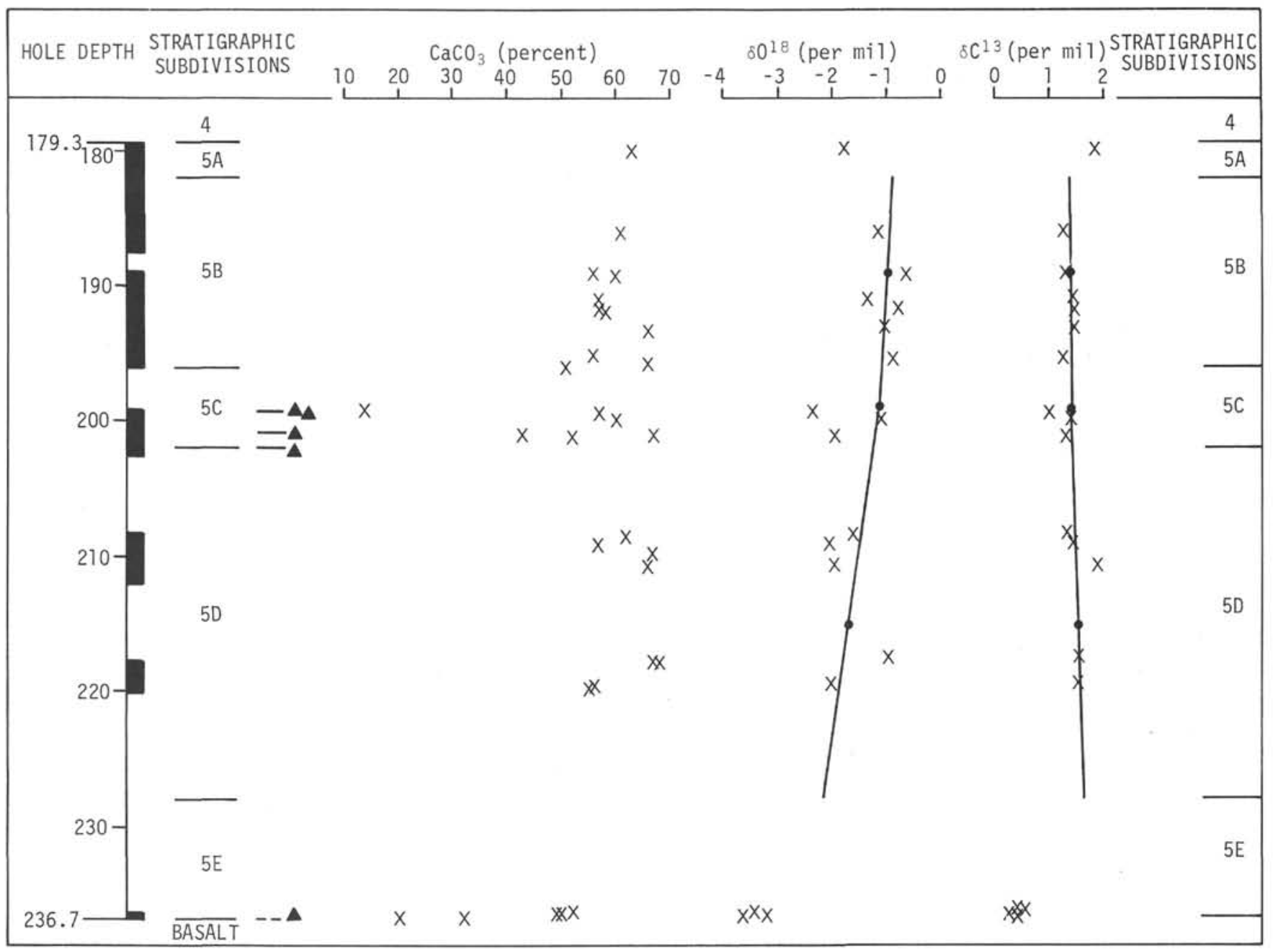

Figure 1. $\delta \mathrm{O}^{18}, \delta \mathrm{O}^{13}$, and $\% \mathrm{CaCO}_{3}$ versus hole depth for Unit 5, Site 287, Coral Sea Basin.

Subunit 5E: (Hole depth, 228-236 m): Olive-gray clay nanno-chalk to nanno-clay. This differs from other subunits in its olive-gray color, the presence of layers of lithified chert nodules, and an abundance (estimated $40 \%$ ) of the volcanically derived authigenic minerals montmorillonite, cristobalite, and zeolites.

Carbonate percentages are moderately constant throughout Subunits $5 \mathrm{~A}$ to $5 \mathrm{D}$ averaging $60 \%$ (Figure 1). The greatest fluctuations from this average occur in Subunit $5 \mathrm{C}$ adjacent to the layers of chert nodules (50\% to $70 \%$ carbonate) and within the chert itself (14\% carbonate in one sample). Carbonate percentages are considerably lower in Subunit 5E (average 40\%).

All subunits appear evenly semilithified on visual examination except for lithified layers in Subunits 5C and $5 \mathrm{E}$. Microscopic examination shows a slight increase in lithification from Subunit 5B (Figure 2) to Subunit 5D (Figure 3). One sample from Subunit 5A shows a reverse trend with $5 \mathrm{~A}$ slightly more lithified than $5 \mathrm{~B}$. Subunit $5 \mathrm{E}$ is more lithified than other subunits (Figure 4), the greatest degree of lithification of nanno-chalk occurring near basement and chert nodules (Figure 5). The increase in lithification throughout Unit 5 is seen as increasing solution of nannofossils and increasing recrystallization as encrusting granular calcite and grain cementation.

\section{OXYGEN AND CARBON ISOTOPE COMPOSITION}

Oxygen isotope values from the Eocene chalks at Site 287 are up to 1.0 per mil more negative than values from sediments the same age elsewhere in the tropical west Pacific (unpublished analyses DSDP Sites 57, 63, 64). At Site $287 \delta \mathrm{O}^{18}$ values progressively become more negative downhole from Subunit $5 \mathrm{~B}$ (average $\delta \mathrm{O}^{18}:-0.99$ per mil) to Subunit $5 \mathrm{D}$ (average $\delta \mathrm{O}^{18}:-1.72$ per mil) (Figure 1). This change in $\delta \mathrm{O}^{18}$ corresponds to a temperature change of $3.4^{\circ} \mathrm{C}$ and a rate of change in temperature of about $1.5^{\circ} \mathrm{C} / \mathrm{m} . \mathrm{y}$. Seven $\delta \mathrm{O}^{18}$ values do not fit this general trend and are more than or about 1.0 per mil more negative than expected. Of these seven values, four are from Subunit $5 \mathrm{E}$ within 0.3 meter of basalt basement and 0.2 meter of chert nodules, two are from Subunit 5C within 0.2 meter of chert nodules, and one from Subunit $5 \mathrm{~A}, 0.6$ meter below the top of Unit 5. Apart from one value which is 0.8 per mil more positive than expected, all other values vary less than 0.5 per mil from the general trend. $\delta \mathrm{C}^{13}$ values also show an overall decrease 


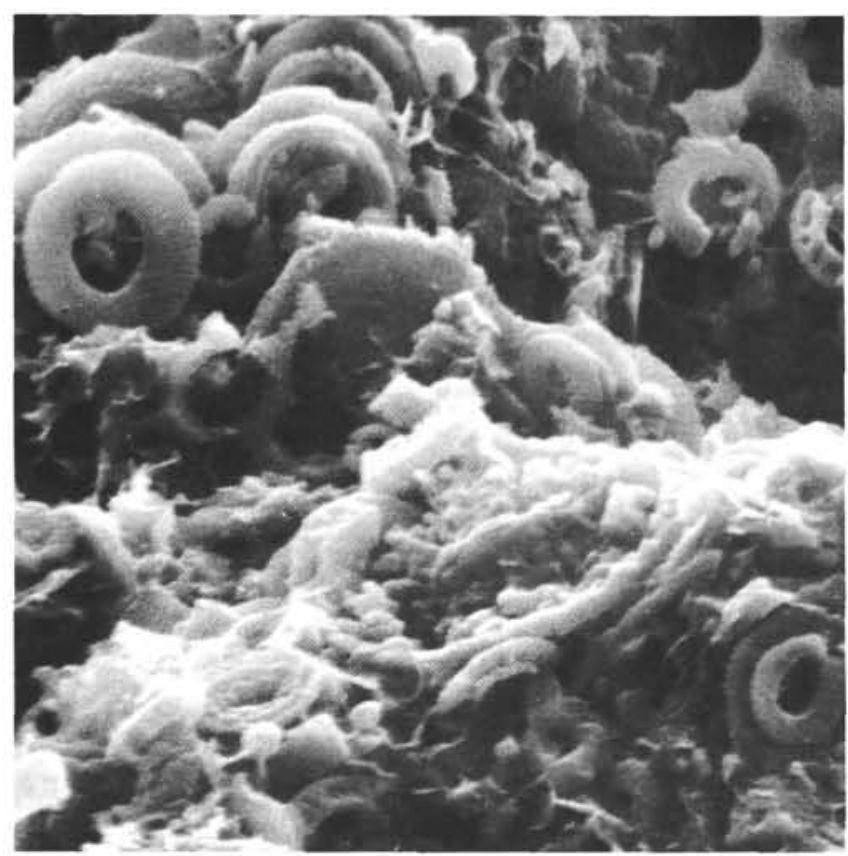

Figure 2. SEM photograph. Site 287; hole depth, 189.5 meters; Unit 5, semilithified nanno-chalk; solution slight, minor amounts of encrusting granular calcite, some grain concentration; $\times 2400$.

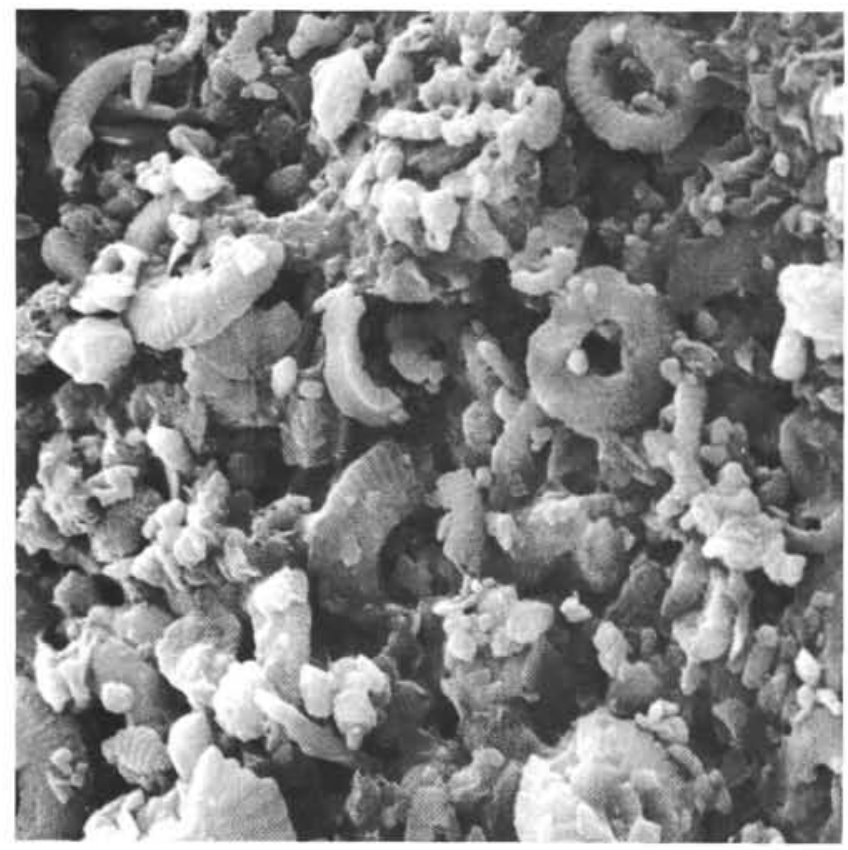

Figure 3. SEM photograph. Site 287; hole depth, 210.9 meters; Unit 5, semilithified nanno-chalk; solution slight to moderate amounts of encrusting granular calcite, some grain cementation; $\times 2400$.

from top to bottom (Figure 1). The values in Subunit 5E are distinctly lower than values from the other subunits. Average values for Subunits $5 \mathrm{~B}, 5 \mathrm{C}$, and $5 \mathrm{D}$ show a slight $(0.16$ per mil) increase downhole.

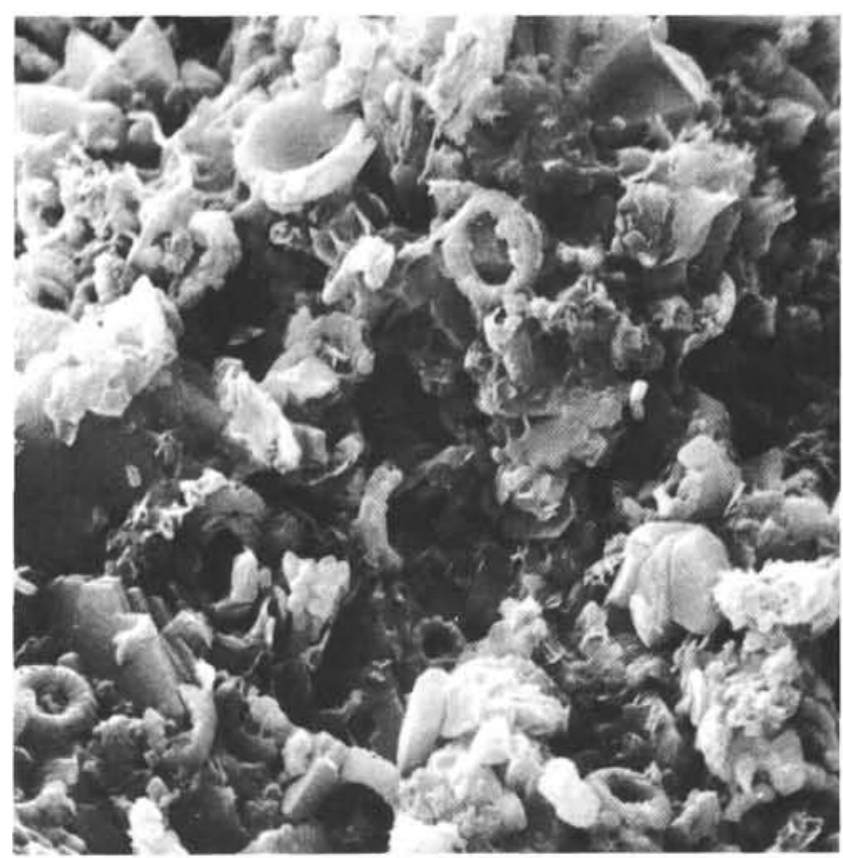

Figure 4. SEM photograph. Site 287; hole depth, 236.3 meters; Unit 5, semilithified nanno-chalk; solution strong and only the most resistant nannofossils remain, moderate amounts of encrusting granular calcite and cristobalite, moderate to strong grain cementation; $\times 2400$.

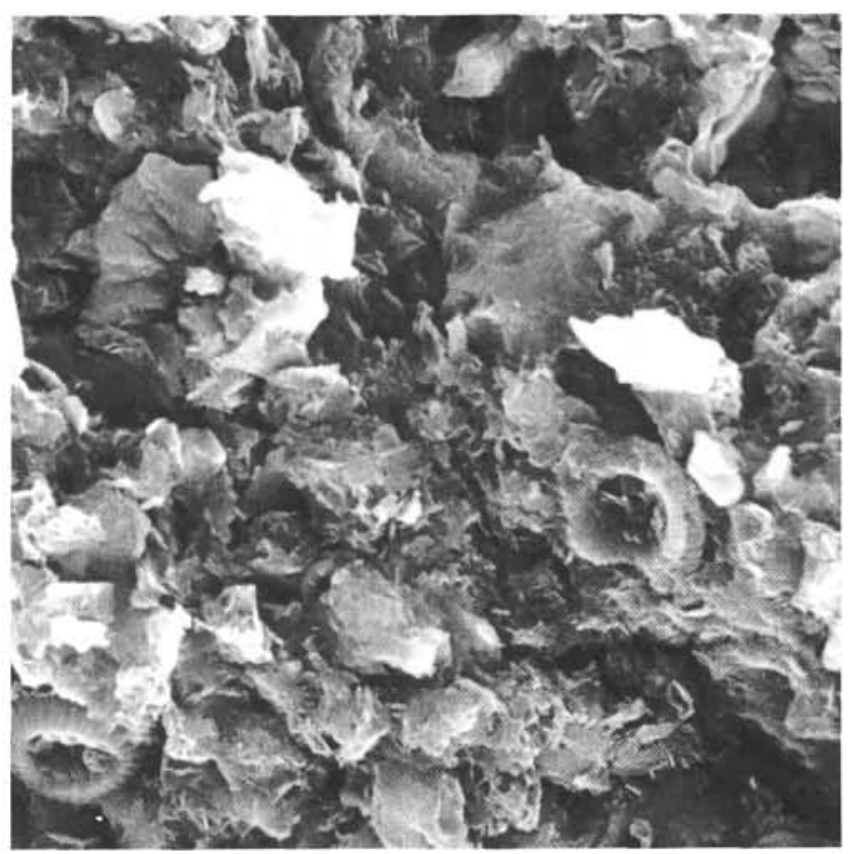

Figure 5. SEM photograph. Site 287; hole depth, 236.6 meters; Unit 5, semilithified nanno-chalk; solution very strong, encrusting cristobalite common, strong grain cementation; $\times 2260$.

\section{DISCUSSION}

The 19 samples analyzed are from the 57 -meter thick Unit 5 chalk which represents about $5 \mathrm{~m}$.y. of middle 
and early Eocene time. These give a detailed look at oxygen and carbon isotope changes in sediments that have been diagenetically altered to varying degrees. At present it is difficult to distinguish between: (1) isotope variations due to climatic effects and/or fluctuations in the isotope composition of surface oceanic water, and (2) isotope variations due to postdepositional alteration. Previous studies have concluded that there has been no significant chemical exchange between oceanic carbonates and interstitial waters, and therefore isotope variations due to diagenesis are insignificant alongside the climatic effects (Coplen and Schlanger, 1973; Lloyd and Hsu, 1972).

However, at Site 287 there are some variations in oxygen isotope values that are too great to explain solely by climate and cannot be explained by volcanism. It is suggested here that under certain conditions diagenesis may leave a detectable isotope fingerprint.

Throughout most of Unit 5, variations in oxygen isotope values are moderate. Over the approximately 2 m.y. period represented by semilithified sediments of Subunits $5 \mathrm{D}, 5 \mathrm{C}$, and $5 \mathrm{~B}$ there is a change with time from average oxygen isotope values of -1.72 per mil to -0.99 per mil. If this were due solely to temperature effects of oceanic water where the carbonate (mostly nannofossils) was originally formed, then a change of temperature of about $3.4^{\circ} \mathrm{C}$ would have occurred at a rate of about $1.5^{\circ} \mathrm{C} / \mathrm{m}$.y. Such a rate of temperature change in oceanic water requires a high rate of heat dissipation, but not beyond what may be expected if temperature effect alone had produced the change. If the nearly uniform lithification of most of Unit 5 sediments has altered the original $\delta \mathrm{O}^{18}$ composition, then the change would be nearly uniform throughout and therefore undetectable. Only if large differences in lithification occur may the relative effects, if any, of diagenesis be detected.

In Subunits 5E and 5C where strongly lithified sediments occur $\delta \mathrm{O}^{18}$ values are more negative than in other subunits. This increased negativity produces a much greater rate of change in oxygen isotope composition between Subunits 5D and 5E than between Subunits 5B and $5 \mathrm{D}$. The rate of change between Subunits $5 \mathrm{D}$ and $5 \mathrm{E}$, calculated from average $\delta \mathrm{O}^{18}$ values and expressed as a change in temperature, is $3^{\circ} \mathrm{C} / \mathrm{m}$.y. This is too high to be due to changes in original oceanic temperature alone and postdepositional processes are considered to have altered to $\delta \mathrm{O}^{18}$ composition in the Subunit $5 \mathrm{E}$ samples, consequently increasing the rate of change. $\delta \mathrm{O}^{18}$ composition of Subunit $5 \mathrm{E}$ may have been lowered by hydrothermal alteration associated with the volcanism that produced the abundant volcanic material in the subunit.

The presence of altered volcanic material and recrystallized carbonate in all subunits indicates that pore solutions have been active throughout Unit 5. The presence of layers of chert nodules and limestone indicates that these pore solutions have been much more active at preferred levels within the unit (Heath and Moberly, 1971). During the alteration of volcanic material to montmorillonite, zeolites, and cristobalite, the $\delta \mathrm{O}^{18}$ composition of pore solutions would have been lowered with respect to normal oceanic water. The recrystallized carbonate precipitated from these pore solutions would have a more negative $\delta \mathrm{O}^{18}$ composition than primary carbonate. It is suggested here that as some recrystallization has occurred throughout Unit 5, the $\delta \mathrm{O}^{18}$ composition of all these sediments has been slightly lowered. Near the chert layers the greater lowering of $\delta \mathrm{O}^{18}$ (about 1.0 per mil more than the semilithified nanno-chalk) has been due to the greater amount of recrystallization that has occurred at these levels.

The greater degree of alteration and lower $\delta \mathrm{O}^{18} \mathrm{com}$ position in Subunit 5A than in 5B suggests that pore solutions have been more active at the top of Unit 5 than immediately below. The preference of pore solutions for this level may be due to the presence of the uncomformable contact of Unit 5 with Unit 4.

\section{CONCLUSIONS}

The relationship that exists between lithified sediment and low $\delta \mathrm{O}^{18}$ composition is attributed to a lowering of $\delta \mathrm{O}^{18}$ by solution and recrystallization of carbonate. $\delta \mathrm{O}^{18}$ values in the semilithified sediments probably have also been lowered, but to a lesser extent than in the lithified sediments. As differences in lithification throughout most of the unit are small, the lowering of $\delta \mathrm{O}^{18}$ values would have been to much the same extent. Values in Subunit 5D have probably been lowered slightly more than those in $5 \mathrm{~B}$. However, the original $\delta \mathrm{O}^{18}$ and therefore original temperature of the oceanic water in which the nannofossils lived would have been altered. Variations in lithification will produce variations in $\delta \mathrm{O}^{18}$ composition and apparent variations in the resulting paleotemperature curve. Therefore, when establishing paleotemperatures from $\delta \mathrm{O}^{18}$ composition, allowances must be made for the effect of diagenetic alteration of the sediments studied.

\section{ACKNOWLEDGMENT}

Thanks to Dr. M. Presland and Mr. G. Walker, Physics and Engineering Laboratory, D.S.I.R., Lower Hutt, New Zealand, for use of the scanning electron microscope.

\section{REFERENCES}

Coplen, T.B. and Schlanger, S.O., 1973. Oxygen and carbon isotope studies of carbonate sediments from Site 167, Magellan Rise, Leg 17. In Winterer, E.L., Ewing, J.I., et al., Initial Reports of the Deep Sea Drilling Project, Volume 17: Washington (U.S. Government Printing Office), p. 505-509.

Heath, G.R. and Moberly, R., 1971. Charts from the western Pacific. In Winterer, E.L., Riedel, W.R., et al., Initial Reports of the Deep Sea Drilling Project, Volume 7: Washington (U.S. Government Printing Office), p. 9911007.

Lloyd, R.M. and Hsu, K.J., 1972. Stable-isotope investigations of sediments from the DSDP III cruise to South Atlantic: Sedimentology, v. 19, p. 45-58.

McCrea, J.M., 1950. The isotope chemistry of carbonates and a paleotemperature scale: J. Chem. Phys., v. 18, p. 549. 